\title{
Climate Smart Agriculture? Governing the Sustainable Development Goals in Sub-Saharan Africa
}

\author{
Peter Newell ${ }^{1 *}$, Olivia Taylor ${ }^{2}$, Lars Otto Naess ${ }^{3}$, John Thompson ${ }^{3}$, Hussein Mahmoud ${ }^{4}$, \\ Patrick Ndaki ${ }^{5}$, Raphael Rurangwa ${ }^{6}$ and Amdissa Teshome ${ }^{7}$ \\ ${ }^{1}$ Department of International Relations, University of Sussex, Brighton, United Kingdom, ${ }^{2}$ Department of Geography, \\ University of Sussex, Brighton, United Kingdom, ${ }^{3}$ Institute of Development Studies, Brighton, United Kingdom, ${ }^{4}$ Department \\ of Social Sciences, Technical University of Mombasa, Mombasa, Kenya, ${ }^{5}$ University of Dar es Salaam, Dar es Salaam, \\ Tanzania, ${ }^{6}$ Consultant IFAD, Kigali, Rwanda, ${ }^{7}$ Independent Consultant, Addis Ababa, Ethiopia
}

OPEN ACCESS

Edited by: Jan Verhagen

Wageningen University and Research, Netherlands

Reviewed by:

Pytrik Reidsma,

Wageningen University and Research, Netherlands

Francisco Javier Solorio,

Universidad Autónoma de Yucatán, Mexico

*Correspondence: Peter Newell

p.j.newel/@sussex.ac.uk

Specialty section: This article was submitted to Climate-Smart Food Systems, a section of the journa Frontiers in Sustainable Food Systems

Received: 04 December 2018

Accepted: 28 June 2019

Published: 07 August 2019

Citation:

Newell P, Taylor O, Naess LO, Thompson J, Mahmoud H, Ndaki P.

Rurangwa $R$ and Teshome A (2019) Climate Smart Agriculture? Governing the Sustainable Development Goals in

Sub-Saharan Africa.

Front. Sustain. Food Syst. 3:55. doi: 10.3389/fsufs.2019.00055
This paper examines the political economic and governance challenges faced by African governments in operationalizing Climate-Smart Agriculture (CSA) as part of their pursuit of the United Nations Sustainable Development Goals (SDGs). There is a need to enrich our understanding of the diverse contexts and ways in which governments will have to navigate and address the inevitable choices and conflicts, synergies and trade-offs that will characterize efforts to simultaneously implement these global goals. Here we seek to develop an account of why and how countries are managing the interrelationship between SDGs, particularly those associated with food security and climate action. We develop explanations for the diversity in approaches and provide an initial assessment of what the consequences are for policy and practice. The analysis is informed by the contrasting experiences of four Eastern African countries, Kenya, Tanzania, Ethiopia, and Rwanda, as they seek to build more "climate resilient" food and agricultural systems that are compatible with achieving the SDGs.

Keywords: climate change, agriculture, SDGs, governance, sub-Sahara Africa

\section{INTRODUCTION}

This paper examines the political economic and governance challenges faced by African governments in operationalizing Climate-Smart Agriculture (CSA) as part of their pursuit of the United Nations Sustainable Development Goals (SDGs). CSA has received growing attention in research and policy debates over recent years (Lipper et al., 2014; Karlsson et al., 2018; Newell and Taylor, 2018), and the SDGs increasingly form a key part of the policy goals for many governments (Chirambo, 2018; Haywood et al., 2018). Despite the shared priorities and concerns of many states when it comes to delivering on CSA and SDGs, less is known about the diverse contexts and ways in which governments will have to navigate the inevitable choices and conflicts and synergies and trade-offs to simultaneously implement the global goals, ranging from economic growth to land and water management, and from food and nutrition security to energy access. Beyond mapping linkages, overlaps and areas of contestation, we need an account of why and how countries are pursuing particular initiatives and strategies to manage the interrelationship among different policy goals. This can provide an explanation of the diversity in approach and perhaps most critically, offer an assessment of what the consequences of this are for achieving the intended (and unintended) outcomes. 
Here we look at the contrasting experience of four Eastern African countries; Kenya, Tanzania, Ethiopia and Rwanda, as they seek to build more "climate resilient" or "climate smart" agricultural systems that are compatible with the SDGs, including efforts to simultaneously enhance food security and improve climate action. These countries were chosen to illustrate contexts in which both CSA (in different forms) and SDGs figure prominently in government policy and activities on the ground, and as countries which, despite many similarities, also typify different governance and development models.

Our starting point is that despite the promise of "triple-wins" around poverty alleviation, climate mitigation and adaptation that is associated with CSA (c.f. FAO, 2013a, 2014, 2017a), conflicts and contestations arise around attempts to govern multiple and interconnected policy goals, as demonstrated e.g., in relation to the governance of the "nexus" around water, energy and food (Scott, 2017; Weitz et al., 2017; Allouche et al., 2019). Thus, achieving "climate smart" agriculture in ways which align with other SDGs and with regional commitments, such as those emanating from the Comprehensive Africa Agriculture Development Programme (CAADP) of the African Union, is a complex challenge. Regional and international bodies often have different visions for the future of agricultural development, which in turn has implications for national government policy and programming (Karlsson et al., 2018; Newell and Taylor, 2018).

To understand how these processes play out in different contexts, there is therefore a need to unpack the role of power relations, diverse systems of governance, the uneven insertion of national economies into regional and global political economies, as well as the role of knowledge brokers in shaping whose knowledge informs decision-making and choices about what constitutes CSA, and ultimately, which impacts should be measured and according to whose criteria.

In this paper, we account for differences in the ways in which decision-makers in Kenya, Tanzania, Ethiopia, and Rwanda have sought to address these challenges through a framework which illuminates the crucial importance of four key dimensions: (i) governance and the role of the state, including the nature of bureaucratic politics and the history of state involvement in the agricultural sector (ii) the politics of translation, domestication and the role of sub-national level actors including the role of different levels of decentralization and democratization (iii) policy autonomy and developmental space and how these are affected by the organization of the agricultural sector in the country and levels of aid dependence and trading relationships which affect the degree of developmental space available to states (iv) the political economy of knowledge, focusing in particular on the role of global institutions; whose expertise frames policy options and representations of CSA, and whose metrics and indicators are preferred to measure performance against agreed targets (see Table 1).

We focus here on these aspects firstly, because of the central role of the state as the actor with the formal responsibility to deliver and report on the SDGs and the significance of different systems of governance in terms of how potentially competing goals relate to existing distributions of power across government and ministries charged with delivering on them. Secondly, how global and regional commitments are translated and implemented in practice is a function of who participates in and shapes policy and the degree of devolution and decentralization that exists in a country. Thirdly, the extent to which states can act independently and autonomously in deciding on the future agricultural development of their economies is a function of the trading and aid relationships they have with other countries that have a major stake in which pathway is pursued. Fourthly, knowledge politics has a key role to play in shaping decisionmaking and evaluation about what counts as "climate smart" agriculture and building scientific consensus about viable options that seek to inform policy.

Empirical material in the paper is used to explore and highlight the value of this framework and compare it against the World Bank's CSA Policy Index (World Bank, 2016, 2018). Though these are clearly not the only explanations for diversity in SDG implementation, we argue that they offer a useful starting point for understanding the everyday politics of realizing the goals in practice.

We examine the experiences of our four focal countries in relation to these four dimensions in the coming sections, starting with a brief review of the broader context in which agriculture and climate change are being addressed at the international level in relation to the SDGs. The analysis is a based on analyses across the four countries, written up in separate papers (Ruangwa, submitted to this Research Topic; Mahmoud, submitted to this Research Topic; Ndaki, submitted to this Research Topic; and Teshome, submitted to this Research Topic).

\section{Climate Change and Agriculture}

The intimate relationship between climate change and agriculture is increasingly well-recognized in expert and policy circles. Agriculture is amongst the most significant contributors to climate change, accounting for between 19 and $29 \%$ of total greenhouse gas emissions (Vermeulen et al., 2012). Agriculture is also one of the sectors most vulnerable to the effects of climate change; consuming some $70 \%$ of global freshwater (Braimoh, 2013) and providing subsistence for circa 2.5 billion people globally who depend upon agriculture for their livelihood (FAO, 2013b). In our case study countries, the percentage of population employed primarily in agriculture ranges from $38.1 \%$ in Kenya to $69 \%$ in Ethiopia (FAO, 2018). The impacts of climate change on agriculture in Sub Saharan Africa are expected to be severe, though the levels of vulnerability varies between regions in the countries in question and by factors such as predominant crop type (Adhikari et al., 2015). Nonetheless, the combined impacts on subsistence farming, employment and the regional economy of forecasted climate change scenarios will be serious. Moreover, while climate change affects all countries, it is notable that the impacts of climate change are differently distributed amongst regions, generations, age classes, income groups, and occupations (Olsson et al., 2014).

The Fifth Assessment Report of the United Nations Intergovernmental Panel on Climate Change IPCC (2014) noted that climate change-driven impacts often act as a threat multiplier, compounding other drivers of poverty (Olsson et al., 2014). Many vulnerable and poor people are dependent 
TABLE 1 | A framework for understanding the governance of SDGs.

Governance and the role of the
state
State power and resources
* Shapes ability to lead and implement
visions for CSA.
* Manifest in planning and
priority-setting on CSA.

Ideology/history of state vs. market in agricultural development

* Shapes expectations and roles of public and private actors in delivering on CSA.

* Manifest in roles given to actors in delivering CSA projects and initiatives.

\section{Nature of policy processes/bureaucratic politics \\ * Shapes who participates in policy and which ministries and preferences prevail in CSA-related strategies. \\ * Manifest in battles over authority to manage CSA and finance to support it.}

The politics of translation, domestication and the role of sub-national level actors

Process of domesticating global and regional commitments

* Explains why global and regional initiatives on CSA look so different once refracted through domestic institutions, policymaking processes and political bargaining.

* Manifest in how governments domesticate their internationa commitments and align them with domestic agendas.

Level of democratization and channels for participation and consultation

* Shapes whose voices get heard and reflects degree of central state control over policy on CSA.

* Manifest in degree of participation in policy of civil society and farmers' organizations and the private sector.

\section{Degrees of decentralization and devolution \\ * Shapes balance of power and authority over CSA relevant policy between central and local state (counties and local government authorities). \\ * Manifest in struggles over resources and delegation of responsibility downwards.}

Policy autonomy and developmental space

Political economy of knowledge

\section{Material base of the economy and the centrality of agriculture \\ * The high dependence of these countries on agriculture for growth explains why policy in this area is high politics. \\ * Manifest in regional commitments such as CAADP to boost expenditure on agriculture and increase private investment.}

Insertion in regional and global political economy of trade, production and finance

* Shapes ability of state to depart from preferences of donors and private investors on CSA.

* Manifest in policies which reflect donor priorities and create an enabling environment for private investors.

\section{Developmental space}

* Shapes scope for pro-poor interventions on climate change and agriculture, which might depart from donor or investor preferences.

* Manifest in conflicts over policy priorities and allocations of funding and high levels of representation of donors in policy fora.
Role of global institutions and knowledge brokers

* Control of knowledge about CSA held by actors that finance initiatives in this area confers significant agendasetting power on those actors to shape outcomes.

* Manifest in role of consultants, advisors, trainers in delivering and evaluating programmes according to their preferred indicators of success.

Whose expertise? Relative power of types of actors

* Shapes what counts as CSA and gets evaluated.

* Manifest in technical support, training, reporting requirements and nature of recommendations for action.

\section{What counts as "Climate Smart Agriculture?" \\ * Shapes what gets funded and acted upon and what gets neglected. \\ * Manifest in development of national CSA strategies, contests over which metrics and indices are the right ones and the active presence of key international institutions in capital cities in the region.}

on activities such as agriculture that are highly susceptible to temperature increases and variability in precipitation patterns (Miyan, 2015). Thus, even modest changes in rainfall and temperature patterns can push marginalized people into poverty as they lack the means to recover from shocks. Extreme events, such as floods, droughts, and heat waves, especially when they occur in combination, can significantly erode poor peoples' assets and further undermine their livelihoods in terms of labor productivity, housing, infrastructure, and social networks (Olsson et al., 2014).

The impacts of climate change on food security, combined with the influence of food and agriculture over our collective ability to dramatically lower greenhouse gas emissions, has been recognized by policymakers, and a suite of policies which attempt to square increasing agricultural production with mitigating climate change, as well as becoming more resilient to its effects, have since followed. The regional analysis of the Nationally Determined Contributions (NDCs) for Eastern Africa by the FAO shows that 16 out of 18 countries include the agriculture and/or Land Use, Land Use Change and Forestry (LULUCF) sector in overall mitigation contributions, while all 18 countries include the agriculture and LULUCF sectors in the adaptation component of their NDCs (FAO, 2017b). The focus on agriculture had increased steadily from the mid to late 2000s, with particular attention given to agriculture-climate change linkages during the Durban 2011 Conference of the Parties (COP), including attempts to set up a separate Agriculture Working Programme under the UN Framework Convention on Climate Change (UNFCCC). While this attempt failed, the focus on agriculture has continued to grow, with the Conference of the Parties (COP 22) in Marrakech in 2016 dubbed by some as the "Action for Agriculture COP" (CTA, 2016), which was followed by the Koronivia Joint Work on Agriculture set up at the subsequent COP 23 in Bonn 2017, underscoring the importance of the agriculture sector in adapting to and mitigating climate change.

The Sustainable Development Goals, agreed in 2015, explicitly recognized the "integrated and indivisible" interconnections between sustainability goals, and are novel in the extent to which they attempt to move beyond traditional policy siloes (United Nations, 2015). In particular, the nexus between food, water, energy and climate change is a key example of the need to maximize synergies while minimizing trade-offs between inter-related sustainability issues. Moreover, policies at the regional level, such as the Comprehensive Africa Agriculture Development Programme (CAADP), the Africa Union's flagship development programme to promote agricultural transformation across the region, has also sought to address climate change. For 
example, CAADP hosted the first Africa Climate-Smart Alliance during UN Climate Week 2014, which is aligned to the CAADP framework that seeks to balance trade-offs between economic growth and sustainability.

Despite near consensus surrounding the importance of an integrated approach to climate-resilient agriculture and the existence of opportunities to capitalize on synergies, however, there are a number of crucial trade-offs (Lipper et al., 2014; Karlsson et al., 2018) — for example between the need for water and forest conservation vs. the need to expand agricultural land and provide irrigation (Khan and Akhtar, 2015). Yet pre-existing policy approaches for climate-resilient agriculture such as CSA give few clues for policymakers on how to effectively address the governance challenges inherent in the inter-sectoral focus which climate-resilient agricultural systems require. Moreover, they make little mention of the ways in which policy and governance frameworks would need to adapt in order to successfully implement such synergistic policies, nor of the complex process through which such international goals are domesticated by national governments (Newell et al., 2018).

This lack of clarity highlights the need to explore what happens when global initiatives on climate change and development intersect with national policy contexts with their diversity of actors, interests and politics. It is critical to take account of (i) how decisions are made in practice; (ii) how outcomes are a function of the relations of power and policy networks that shape the prospects of realizing climate change and development goals; (iii) how global drivers of national level climate change debates open up and close down different development pathways; and (iv) how climate change and development outcomes look very different depending on how they are defined and who defines them (Naess et al., 2015).

Given this, the paper addresses the question of how countries navigate such different contexts in pursuing strategies for climate resilient agriculture in line with the SDGs. This raises important questions about how countries "domesticate" regional and international agreements on sustainability and agricultural transformation (such as CAADP and the SDGs) at national level; whose knowledge counts and whose understandings and priorities prevail in defining the "problem" and possible policy response to it; and how trade-offs and conflicts between different pathways around food and agriculture, energy and water are identified, recognized and acted upon (or neglected) and by whom. This in turn implies attention to who participates in or is excluded from decision-making on these initiatives and projects and how far governance systems handling the food-energy-water interactions are shaped and influenced by external actors (such as global institutions and donor agencies). It draws attention to the ways in which the conflicts and trade-offs between CAADP and the SDGs are currently being handled at national level, the consequences of these choices and of course who is affected by these consequences.

The following section introduces the theoretical framework, followed by an empirical analysis of four dimensions that we argue help explain differences and similarities in the governance of climate resilient agriculture across the four countries, namely the role of the state, the politics of translation, policy autonomy and developmental space, and the political economy of knowledge. We conclude by reflecting on the implications of the findings and arguing for a more explicit "foregrounding" of the politics involved in trying to balance often widely divergent goals and interests across climate change, agriculture, and development.

\section{THEORY AND METHODOLOGY: CONCEPTUALIZING THE GOVERNANCE OF SDGS}

There is a growing literature looking at the SDGs and their governance in general, as well as national level analysis of implementation efforts, such as enquiries into the coherence between the water and agriculture sectors against climate change adaptation goals outlined in national development plans (England et al., 2018). Thus, there has been growing emphasis on "synergies" and "nexuses." Yet meeting the SDGs simultaneously brings into sharp relief the trade-offs between them and presents potentially unprecedented challenges for governments in terms of how to design policies and processes that afford a holistic view of their interaction and impact on other resource areas. As Biermann et al. (2017, p. 26) put it, "while the SDGs hold a great potential, their collective success will depend on a number of institutional factors, such as the extent to which states ... strengthen related global governance arrangements, translate the global ambitions into national contexts, integrate sectoral policies, and maintain flexibility in governance mechanisms." Likewise, as Weitz et al. (2017) argue, while the literature on the nexus around waterenergy-food identifies barriers to achieving coherence, it tends to do so without exploring why barriers are present, and what influences them, while ignoring the non-linearity and complexity of governance processes. Key barriers to policy coherence include the unequal distribution of power, voice, access to information, resources, and capability among actors and institutions that inevitably derive from a political process of negotiation among unequal partners (Allouche et al., 2019).

What is missing then, is a deeper analysis of the politics and political economy of why countries are following particular pathways in addressing SDGs the way they do. Not merely noting the differences, but building frameworks of understanding to account for those differences and how, why and for whom they matter. To develop such an analysis we carried out a study across four countries with different systems of governance in relation to the role of the state and civil society, degrees of decentralization, and democratization, diverse forms of integration with the global economy, and differences in the degree and nature of expertise involved in shaping CSA policy with a view to building a framework for understanding some of the key differences in approach between countries (see Table 1). In particular in relation to our first cross-cutting theme on governance and the role of the state we look at: state power and resources; the role of ideology regarding the state, market and agricultural development and the nature of policy processes and bureaucratic politics. Regarding our second theme on the 
politics of translation, domestication and the role of sub-national level actors in domesticating their international commitments and aligning them with domestic agendas we explore level of democratization and channels for participation and consultation as well as degrees of de-centralization and devolution. In relation to theme three on policy autonomy and developmental space we explore: the nature of the agricultural resources-their value and centrality to growth the degree of state intervention in the economy; levels of aid dependence; the nature of a country's insertion in regional and global political economy and the degree of developmental space a country enjoys. Regarding our fourth and final theme on the political economy of knowledge we assess: the role of global institutions and knowledge brokers; questions of knowledge politics and expertise and different interpretations of what counts as climate-smart agriculture.

To make sense of these different dimensions our conceptual framework draws on literature across three complementary theoretical areas. Firstly, in order to understand governance and the role of the state in relation to managing SDG implementation in relation to climate and agriculture we draw on work on policy processes (Keeley and Scoones, 2003) and the political economy of climate compatible development (Quan et al., 2014; Tanner et al., 2014; Naess et al., 2015; Phillips et al., 2017). This helps us to understand the relations of power which "mediate the winners, losers and potential trade-offs between different goals, and the political and institutional factors which enable or inhibit integration across different policy areas" (Naess et al., 2015: 534). From this perspective, policy development and implementation processes are best described as incremental, complex and "messy," involving actors with often competing goals and interests, which deploy knowledge and expertise in strategic ways (Keeley and Scoones, 2003; Tanner and Allouche, 2011).

Secondly, we engage with work on the "politics of translation" (Newell, 2008) and the "domestication" of global commitments to sustainable development. Here the term "polycentric governance" has been used to describe how a given policy or intervention blends together actors across different scales of implementation that fuse the agency and funds of public and private actors (Cole, 2015; Sovacool et al., 2017). More specifically in relation to climate change, we engage with insights from political ecology and political economy to climate change adaptation in particular (Taylor, 2015; Sovacool and Linnér, 2016), and to climate-resilient and climate-compatible development in general (Rai and Fisher, 2016; Nunan, 2017). We highlight the value of political ecology approaches that "situate local processes within a multi-scalar series of causal forces" [(Taylor, 2015), p. 5].

Thirdly, to appreciate the economic and structural dynamics which impact upon countries' degree of policy autonomy and developmental space to manage the synergies and trade-offs around climate change and agriculture in ways which align with domestic priorities, we draw on insights from the political economy of development (Wade, 2003; Gallagher, 2005). These help to illustrate that the ways in which trade-offs between SDGs are resolved is a function of factors such as a country's location in the global political economy (e.g., level of aid dependence and flows of foreign direct investment (FDI) and how much policy autonomy exists to address the tensions inherent in the SDGs in ways that accord with domestic priorities, rather than the preferences of donors and transnational agribusiness actors. Where they are heavily aid dependent and tied to the agendas of development banks, it becomes easier to understand how the predominance of market-liberal framings that we observe globally gets replicated regionally and nationally through CAADP and national CSA strategies (Newell et al., 2018).

Finally, to understand how knowledge frames policy, pathways and understandings of what counts as climate resilient agriculture in a development context, we draw on emerging literature examining concepts, synergies as well as trade-offs. The idea of linking adaptation, mitigation and development gained momentum first with the concept of "development first" (Beg et al., 2002; Davidson et al., 2003), and has since taken the form of policy goals, including low carbon climate resilient development (Ellis and Baker, 2009); climate compatible development (Mitchell and Maxwell, 2010), and even Climate Smart Agriculture (FAO, 2013a). This has been followed by, over the past few years, assessments of evidence of efforts to implement such "triple wins," including more critical research on trade-offs (e.g., Suckall et al., 2014; Nunan, 2017; Karlsson et al., 2018).

We undertake an analysis of how Kenya, Tanzania, Ethiopia and Rwanda are approaching policies for "climate-smart" or "climate-resilient" agriculture in order to illustrate the value of a framework combining the three elements described above. Though facing similar generic challenges around how to build more climate resilient and compatible agricultural systems, these countries afford useful insights around the importance of state-led development pathways (Ethiopia, Tanzania, and Rwanda) vs. more market-led approaches (Kenya), different degrees of decentralization (e.g., Kenya vs. Ethiopia), different degrees of space for civil society participation, and varying degrees of donor dependence. We focus in turn on governance and the role of the state, the politics of translation, policy autonomy and development space in terms of the position of these countries within global relations of aid and trade and finally knowledge politics and the role of expertise in shaping pathways. The research was undertaken through an analysis of key policy documents, discourse analysis of dominant framings, a participatory workshop involving participants from each country case study and interviews with key actors involved in developing policies in the climate and agriculture domains including policy makers, government agency staff, donor staff and researchers (see above-mentioned country case study papers for further detail).

\section{RESULTS AND DISCUSSION}

\section{Governance and the Role of the State}

National policy contexts with their diverse set of actors, interests, and politics are a useful place to begin to understand the varying dynamics and approaches taken to shaping climate resilient agricultural policies (Naess et al., 2015). A common feature across the four countries in question is the approach of state-led development frameworks and "visions" such as Kenya Vision 2030, Tanzania Vision 2025, Rwanda Vision 2020, and the Ethiopia Growth and Transformation Plan 2025, of which the Climate Resilient Green Economy Plan is a component. 
Whilst each state-led vision or plan is distinct, a common theme across these four countries is the aspiration to forge new development models; incorporating the challenge of climate change and sustainable development, whilst at the same time targeting ambitious rapid economic growth, such as planning to achieve middle-income country status over the course of the plan.

Such strategies reveal some of the dynamics of governing the complex trade-offs around the relationship between climate change and agriculture. In Ethiopia, for example, the Climate Resilient Green Economy (CRGE) is a key climate strategy that guides other growth and development plans (FDRE, 2012). The strategy recognizes that Ethiopia will be highly vulnerable to the impacts of climate change. The vision is to build a middle income economy by 2025 in a way that is both resilient to the negative impacts of climate change, while at the same time reduces greenhouse gas emissions to achieve; “...adaptation to climate change and mitigation of greenhouse gases emissions, reducing greenhouse gas emission through enhancing productivity of the crop and livestock sub-sectors that improve food security and income of farmers and pastoralists, protecting and rehabilitation of forests for their economic and ecosystem services" (National Planning Commission, 2015, p. 14-15). The strategy has four major pillars, each with lead institutions including agriculture and livestock; water and energy; industry and transport; and health. Each institution and region is expected to establish a CRGE Coordination Unit within the Environment, Forest and Climate Change Directorate or Bureau.

Kenya's Climate Smart Agriculture Program (CSAP 20152030) envisions "a climate resilient and low carbon growth sustainable agriculture that ensures food security and contributes to national development goals in line with Kenya Vision 2030" and also is thought to be crucial for coordinating domestic and international CSA interventions. In the preparation of the CSAP (2015-2030) Kenya combined the efforts of two ministriesthe Ministry of Environment and Mineral Resources and the Ministry of Agriculture, Livestock and Fisheries. Technical and financial support were obtained from a wide range of sources including NEPAD Climate Change Fund, Common Market for Eastern and Southern Africa (COMESA), the East African Community (EAC), and the CGIAR Research Program on Climate Change, Agriculture, and Food Security (CCAFS). The four strategic priorities of CSAP are (i) create national systems to enhance CSA best practices, technologies and approaches; (ii) create value chain systems in which both the public and private sector become important actors; (iii) support demand-driven research for development and innovation; and (iv) improve and sustain agricultural advisory services.

In Tanzania, and in addition to the Vision 2025, the government has sought to align responses to climate change and the promotion of CSA with broader investment and industrial strategies. Initiatives include the finalization of the Agricultural Sector Development Programme (ASDP II), which is intended to run for from 2017-2026 taking into account climate change. There is also the Agriculture Sector Environment Action Plan aimed at promoting sustainable production; the Climate Smart Agriculture Programme; and the Tanzania Agriculture and Food Security Investment Plan which also identifies climate change as an issue of concern. Climate Smart Agriculture Guidelines to guide implementation of the CSA Programme (2015-2025) have also been developed, identifying six strategic priorities as sources of Tanzania's agricultural development and growth in a changing climate, as follows: (1) improved productivity and income; (2) building resilience and associated mitigation co-benefits; (3) value chain integration; (4) research for development and innovations; (5) improving and sustaining agricultural advisory services; and (6) improved institutional coordination.

In pursuing these goals and dealing with agriculture's relation to other sectors, states have sought external funding. For example, the Simiyu Climate Resilience project in Tanzania with KfW Development Bank was recently approved by the Green Climate Fund Board with financing of US\$102.7 million and concentrates on ensuring water availability for farming and other uses. Likewise, the Resilient Natural Resources Management for Growth (REGROW) project is being implemented in rice production schemes to encourage farmers to sustainably use water for irrigation. Most of these initiatives are funded by the donor community through multilateral, bilateral, and other arrangements, while some are government funded. Why this matters in terms of policy autonomy is addressed further below.

In Rwanda meanwhile, the government has over the last decade intensively embarked on investments in CSA practices such as land husbandry, water harvesting, and hillside irrigation to increase resilience to climate change, reduce water erosion and soil loss, halt land degradation, and increase land productivity. Programmes that mitigate emissions such as one cow per poor family, zero grazing and the use of droppings for household bio-gas production in intensive livestock systems have also been implemented. Agroforestry has also been promoted, whereby the government have pledged to restore 2 million of hectares of land mainly through agroforestry. Government initiatives also include the development of the Rwanda National Strategy on Climate Change and Low Carbon Economy in 2011 (REMA, 2011) and the establishment of a green fund (FONERWA) to support green growth in Rwanda over the next 50 years while serving as touchstone for Africa and the rest of the world.

What these national strategies and plans often disguise are the bureaucratic turf wars between ministries or, more benignly, the contested division of labor among them, which lie behind the production of these strategy documents and which set in train their implementation. For example, an officer from the Vice President's Office-Division of Environment in Tanzania commented that the "power struggle within departments and institutions leads to and/or intensifies conflicts [where] each one would like to be seen as a winner." Similarly, according to a key informant from the Ministry of Industry, "industry focuses more on mitigation than adaptation and agriculture the other way round" (pers comm. 2017). Besides differences in mandate and approach to the issue, there are often clear bureaucratic power imbalances which underlie these tensions. In Rwanda, the Ministry of Finance and Economic Planning (MINECOFIN) is centrally involved in the process of domestication of international commitment such as the SDGs. It provides orientation from the integration of SDGs into sector strategy up to the level of its reporting. It has already, through the support 
of the UN, carried out a SDGs Assessment Report showing indicators and targets already incorporated in the national planning system. It highlights what each sector is supposed to respond to. Agriculture and environment sectors have specific goals within SDGs goals with indicators and targets that need to be incorporated and addressed in their planning processes.

In other cases, bureaucratic politics are reflected in sector-based planning which undermines the prospects of more integrated and holistic ways of thinking about SDG implementation. Lack of policy coherence also results from conflicts within governments (horizontal governance) as well as across levels of governance (vertical governance) over authority, priorities and resources. In this way, narrowly conceived sectoral policies can undermine integrated development pathways by failing to take into account other sectors' interests, meaning that sector-based planning disaggregates stakeholders' demands and development objectives into food and agriculture, energy, and water. In addition, sector budgeting and implementation induces duplication of efforts and minimizes the chances of tapping opportunities for a more holistic approach to development pathways. In Tanzania, for example, a representative from the Economic and Productive Sector-President's Office, Regional Administration and Local Governments put it as follows: "The challenge we have had as a country at both national and local levels, is that we always plan sector-wise and not integrative. That is why during implementation we have conflicts among and between sectors" (pers comm. 2017).

\section{The Politics of Translation, Domestication and the Role of Sub-national Level Actors}

Another key area of state power, building on the theme of autonomy, is the politics of translation (Newell, 2008). This refers to the processes and means by which governments domesticate regional and international commitments. It helps us to understand why global initiatives around CSA or the SDGS or regional ones such as CAADP look so different once refracted through domestic institutions, policymaking processes and political bargaining.

Ethiopia was one of the first countries to sign up to the Maputo Declaration on Agriculture and Food Security in 2003 [Assembly/AU/Decl.7(II)] when African Heads of State and Government initiated the Comprehensive Africa Agricultural Development Programme, but its own national CAADP Compact required a lengthy process of consultation and was not signed until 2009. After the country found itself behind neighboring states in meeting its commitments, the Policy and Investment Framework (PIF) was introduced in 200910. The PIF helped to translate the four CAADP pillars into the Ethiopian context. Presently, a process is underway to prepare Ethiopia's National Agricultural Investment Framework (NAIF) which aims to "domesticate" the Malabo Declaration on Accelerated Agricultural Growth and Transformation for Shared Prosperity and Improved Livelihoods [Assembly/AU/2(XXIII)] (African Union, 2015). That declaration, which was adopted by African Heads of State and Government at the 23rd African Union (AU) Summit in 2014, repositioned agriculture as a priority on the continental development agenda and reaffirmed the CAADP commitments for another 10 years.

Likewise, the Head of the Environmental Section in the Ministry of Agriculture in Tanzania suggests the key elements of the CSA programme derive directly from regional and international agreements. "Our new policy, the Climate Smart Agriculture Programme, and the Resilience Plan are all a reflection of the CAADP, the Climate Change Convention and other international and regional agreements on environment, climate change and sustainable development" (pers comm. 2018). The fact that these agreements demand and require very different things that may be in tension with one another is not acknowledged in this instance. Hence, while the climate regime demands sharp reductions in greenhouse gas emissions, CAADP and regional common market organizations prioritize new growth opportunities through the intensification of expert-oriented and often emissions-intensive forms of agricultural production.

To some extent, the nature of implementation is set by the agreement itself. As a representative from the Division of Environment in Vice President's Office in Tanzania comments, for example: "Domestication of international agreements is done depending on the nature and requirement of the agreement itself. There are agreements which require cabinet approval; others require ratification by the parliament, while others may not even require taking them to the cabinet or parliament" (pers. comm. 2018).

Nevertheless, interested external parties associated with these agreements can exercise considerable influence in ensuring that governments implement the agreements according to their preferences. For example, the CAADP Secretariat at the African Union Commission has provided technical support to Rwanda through organizing and conducting trainings of local experts and ensuring a CAADP Country Team exists with public, private and civil society involvement. Furthermore, the secretariat has developed guidelines for countries on how to domesticate CAADP performance indicators. Secondly, each country has responsibility to report once in every 2 years on the implementation progress of CAADP commitments. Upon the reporting, a new scorecard rating methodology is being used to rate the country performance against the established indicators. This kind of ranking and disciplining of countries according to their delivery on investment targets is revealing of an important power dynamic and perhaps provides stronger incentives to meet CAADP targets than to ensure their compatibility with SDG goals over which there is currently less formal oversight.

The domestication of international and regional agreements has had a number of influences on approaches to food and agricultural policy formulation and implementation. As a result of agreements such as the CAADP, there is currently increased investment by governments and other stakeholders, such as the private sector, in the agriculture sector. These investments can take different forms, such as supply of subsidized inputs, employment of agricultural extension staff to farmers in rural areas, supply of subsidized machinery for cultivation, processing and value addition of agricultural produce and provision of extension and advisory services to farmers, including provision 
of climate services to support adaptation. The assumption is that this will attract agro-based investments thereby increasing commercially oriented agricultural production. Indeed, there is an increased role for the private sector in various ways such as through supply of inputs in order to increase productivity at the local level; promotion of large scale farming in order to transform agricultural production for assurance of food and nutrition security; agro-processing, in line with strategies for industrial development; and marketing of agricultural produce and agro-processed products.

Though many of these patterns of domestication are similar across all the country cases, degrees of democratization, and openness to public participation do differ, with important implications for whether, how and by whom trade-offs are negotiated and resolved. In terms of civil society, for example, the "Climate Change Forum Ethiopia" (CCF-E) was launched in 2007 initiated by Oxfam America and endorsed by the Federal Government. By 2013, CCF-E had grown into an initiative with over 100 individual and organizational members. Its main objective is to advance advocacy in the area of climate change adaptation and mitigation, through research and awareness raising campaigns on climate change issues. Its research aims to inform policy at the national and international levels and provide the government with research and policy analysis for the UNFCCC negotiations. CCF-E collaborates with government institutions, such as the Ministry of Agriculture, and Natural Resources, to carry out climate change vulnerability assessments and to implement projects aimed at reducing vulnerability. At the same time, Berhanu and Poulton (2014) have observed that since 2005 the Ethiopian Government has sought to control the policy advocacy activities of non-government organizations through a mandatory re-registration process. Due to this constraining environment, beyond examples such as CCF-E, the participation of civil society organizations (CSO) has diminished, shifting the balance of power toward the government, such that key decisions remain in the hands of the government. For example, none of the non-governmental or donor organizations are named on the list of institutions assigned to lead or support the implementation of the adaptation plan for climate change.

The absence of significant civil society participation in state decision-making in countries such as Ethiopia, or its selective engagement in other countries in the region, carries important implications for which voices get represented in debates about agriculture and climate change. Patterns of exclusion affect in particular the groups that are most vulnerable to climate change, as well as the policies set up to address it. Many of the policies affect the smallholder farmers, fisher communities as well as pastoral and agro-pastoral communities, but they themselves are not part of the decisions. Similarly, in 2005 the decision of the Government of Tanzanian to evict all pastoral and agro-pastoral communities from one area in the southern highlands (URT, 2006, 2009) was criticized due to lack of consultations and poor preparations of the areas where the evicted pastoralists would be taken. Speaking of the fate of pastoralism in Tanzania, Kateka (2016, p. 173) suggests that "Pastoralists are not sufficiently involved in policy making, local government planning processes; village and district level plans often do not benefit from, or support, their productive strategies." Hence, much as the local communities are among those most seriously vulnerable to climate change and those most directly affected by decisions to govern natural resource use, they are frequently overlooked or actively bypassed in state decision-making at all levels.

But spaces have also opened up for some farmers' organizations. In Tanzania, this includes farmers and their farmer or pastoral organizations (both crop and animal production), such as Mtandao wa Vikundi vya Wakulima Tanzania (MVIWATA) (a national farmers' organization), the Agricultural Council of Tanzania (ACT), the Tanzania Chamber of Commerce Industry and Agriculture (TCCIA), as well as agro-industry and agro-processing actors, including agribusiness dealers, exporters, processors, importers, distributors, service providers, and related organizations, and financial institutions directly or indirectly involved under the climate change and agriculture umbrella. They are key to supporting farmers, particularly with regard to accessing agricultural inputs from the government and other private service providers. In terms of their impact on policies, they currently have a particularly strong influence at the local level where political rallies and meeting are held especially during elections. Their agenda seems to be heard strongly in parliamentary sessions and during political rallies.

Moreover, the process of domesticating international programmes also creates openings for civil society actors to hold governments to account for their delivery of commitments contained in international agreements. As a representative from the Division of Environment in the Vice President's Office in Tanzania commented: "Domesticating an agreement always becomes like a pledge. This is because the process of negotiating, adopting and domesticating is always open for other stakeholders to follow at national level. Therefore, as soon as you domesticate, it is like you have entered into agreement with stakeholders. They will always be following up what you do to implement the agreement. It is for this reason that you will always hear CSOs ask the government what they have done to achieve the 10\% of GDP for the agriculture sector budgets as per the Maputo/Malabo declaration, which intended to incentivize more investment in agriculture while giving governments leeway in terms of how exactly to prioritize and allocate these investments. This is a good example of how the domestication triggers monitoring from part of the players. Domestication is actually a commitment both domestically and internationally" (pers. comm. 2018).

When considering the state it is important not to neglect the sub-national level of decision-making authority where important differences are observable across the country cases. Local Government Authorities (LGAs) are important and key in implementing policies and programmes. For example, the National Agricultural Policy in Tanzania makes these LGAs responsible for promoting social and economic development; designing and implementing sector plans; supervising the implementation of laws, statutes and regulations relevant to the sector; supervising and coordinating the delivery of extension services; mobilizing resources (financial, human and facilities/equipment) for local development programmes; administration of villages for the purpose of stimulating sustained development; and land administration, land use 
planning and management for effective and sustainable land utilization (URT, 2013).

In Rwanda meanwhile, all 30 Districts (local administrative entities) usually develop their own District Development Plans (DDPs) building on national sectoral targets. Districts, therefore, have some autonomy to domesticate these national targets according to local conditions and priorities. More specifically, each district will respond to the national targets according to the existing opportunities and challenges within their own districts. For example, a rural district with relatively higher land availability and having issues of increasing droughts will have to prioritize the climate resilient agriculture actions as set by the Rwandan Government's Strategic Plan for Agricultural Transformation 4 (PSTA4), covering the period of 2018-2024.

Devolution and decentralization has gone furthest in Kenya, however, following the introduction of a new constitution in 2010 that devolved power to a county level (Government of Kenya, 2010). As it pertains to agriculture, although government ministries have the responsibility to set the policy, implementing agricultural policy is devolved to the county level. Because of this, the ministries at a national level are solely responsible for guiding policy and strategy, and not for reconciling the synergies and trade-offs of CSA, or the inconsistencies and disconnects between regional and international policy (Newell et al., 2018). The impact of this is that the hard choices are being passed down to a more local level, where more contextualized decisions can be made, but from where it is harder to see the bigger picture, and where there is less technical and administrative capacity.

\section{Policy Autonomy and Developmental Space}

How the relationship between SDGs is governed and by whom in relation to climate change and agriculture is not just a function of government institutions, decision-making processes and the politics of how commitments are translated into practice. Here we also consider economic explanations including the material base of the economy and how far it is reliant upon agriculture, and in particular certain forms of agriculture, as well global economic factors which help to determine the degree of policy autonomy and developmental space countries have to develop their preferred agricultural development pathway.

Firstly, it is important to appreciate just how central a role agriculture plays in all of the economies considered. Yet though the expansion of export-led industrial agriculture is represented as a generic national interest, it belies a number of potential trade-offs which take different forms at national level. For example, in Tanzania, conflicts and trade-offs exist between water and forest conservation and expansion of agricultural land, irrigation and livestock production. Similarly, in Ethiopia both small-scale agriculture, and more recently largescale investments, have accelerated the deforestation process which contravenes the country's carbon sequestration or storage objectives (Sorecha, 2017).
In many countries in the region, the drive to commercialize agriculture is producing new exclusions. For instance, Tanzania has adopted a number of policies which aim to transform agricultural production. Recently, the government has concentrated on ensuring the country reaches a middleincome status through the promotion of industrialization in which revitalizing agricultural production is a key component of achieving this goal. This involves a clear shift toward more support for large scale farming rather than small scale farmers. Some examples demonstrate this shift. In 2009, the Government of Tanzanian adopted the Kilimo Kwanza (Agriculture First) to accelerate agricultural transformation. The stated aim was to modernize and commercialize agriculture in the country. While this in principle involved both small- and large-scale agriculture, the main focus in practice was on large-scale commercial agriculture. The fifth pillar of the resolve focuses on amending the Village Land Act of 1999 to open up the access of village land to large scale investments. Therefore, through the initiative, it will be easier for village land to be taken and transferred to large-scale investors hence affecting smallholder farmers who stand to lose (Vorley et al., 2012). Activities under this pillar also include allocating land to a land bank, again with the aim of facilitating land access for commercial operators. To implement the initiative, the Southern Agricultural Growth Corridor of Tanzania (SAGCOT), which is a public-private partnership, was launched in 2010. Its aim is to catalyze private investment and improve agricultural productivity with a focus on the development of large-scale farming and the involvement of small-scale producers in the supply chain. This has led to concerns that it is going to open up arable land for commercial operators leaving out the majority of smallholder farmers (Vorley et al., 2012; Smalley, 2017).

Rwanda's Fourth Strategic Plan for Agricultural Transformation 2018-2024 concluded that increasing the resilience of Rwanda's productive system, including to climatic risks, is a key determinant for sustainable production and productivity increases and greater food and nutrition security. Based on that, and strongly echoing development bank and donor prescriptions around private-sector led transformations in the agricultural sector, the strategy embraces different climate smart initiatives across its four priority areas, namely innovation and extension; productivity and resilience; inclusive markets and value; enabling environment and responsive institutions. This is unsurprising given that a task force was established under MINAGRI leadership to guide the development of PSTA 4, including membership from the Rwanda Agriculture Board, the National Agricultural Export Development Board NAEB, and a nucleus of development partners (European Union, FAO, World Bank, UK Department for International Development (DFID), and US Agency for International Development (USAID). Additionally, this strategy recognizes the multi-dimensional nature of the agricultural sector with a reference to CAADP and the Malabo Declaration Commitments, as well as the SDGs, through which a close coordination of the agriculture sector with other relevant ministries, the private sector, and civil society organizations is critical. 


\section{Developmental Space}

The concept of "developmental space" is often used to describe how much freedom of maneuver developing countries have to pursue their preferred developmental pathways given the constraints they face and their dependence on private capital or foreign aid from more powerful countries (Wade, 2003; Gallagher, 2005). This differs from the domestication and translation described above in that its focus is on economic relations and dependencies.

The economic position of countries in the region in terms of trading relations and levels of aid dependence has a significant impact on how trade-offs among the SDGs are handled and governed. Deliberations about how to promote CSA in the context of the SDGS do not take place in a vacuum. External actors play an important role in advancing their preferences. For example, Feed the Future, the major USAID initiative in Ethiopia (and is being implemented in many African countries) includes programmes such as the Value Chain Activity (Fintrac Inc.) while DFID has a "Land Investment for Transformation (LIFT) programme." The objective of the programme is to improve the incomes of the rural poor and vulnerable groups in Ethiopia and enhance economic growth, through second-level land certification, and improved rural land administration. The programme team is working with the government of Ethiopia to improve the effectiveness of the rural land sector through increased security of land rights and to enhance the productivity and incomes of the farmers, especially women and vulnerable groups. The emphasis on securing property rights and enhancing productivity for growth also resonates strongly with World Bank approaches to the sector (Taylor, 2018).

There are a variety of mechanisms for building and communicating the consensus of the donor community to national governments. Development organizations in Ethiopia engage with the Government collectively through three coordination mechanisms such as the Rural Economy and Food Security (RED\&FS) Sector Working Group and the Development Assistance Group (DAG) which brings together all development organizations supporting projects and programmes-small or large. The third is the PSNP Donor Coordination Team (DCT) hosted by the World Bank. It provides technical support to the Food Security Coordination Directorate of the MoANR during the design, implementation, and monitoring and review of the program. In Tanzania, a similarly conceived Development Partners Group on Environment, Natural Resources and Climate Change (DPG-E) plays a key role in shaping policies and supporting their implementation. In Rwanda, a Sub-Working Group on Climate Change chaired by MINAGRI is co-chaired by a DFID representative where key stakeholders exchange views on how to inform and support the agriculture sector through identified climate change challenges. The meetings are held on a quarterly basis and development organizations include DFID, FAO, the International Fund for Agricultural Development (IFAD), USAID, and the World Bank, among others.

In general, these institutions play a central role in shaping agricultural and environmental policies since they are actively involved in policy and strategy formulation and implementation. Furthermore, they are also closely involved during the implementation of the strategic actions through designing different projects in line with their interest and priorities. In other words, the sector strategy priority actions are the ones that theoretically drive the design and implementation of the different development projects funded by donors, including the ones addressing CSA. However, in reality according to most interviewees, the donors' priorities and interests come first during the design and financing of projects.

The degree of autonomy from donor interests differs between the countries, however. Whilst donors play a key role in Kenya and Rwanda, in Ethiopia, when it comes to the fundamental principles, structures and components of programs, the government remains in control despite being heavily aid dependent. This "autonomy" is enshrined in the developmental state paradigm reflected in projects that have the potential to organize society around its vision, and the autonomy to insulate itself against the narrow interests of specific actors and to secure broad support (Oqubay, 2015). With respect to climate change, the government's move has been very strategic. When it became clear that the developed countries would compensate the developing countries for their efforts to sequester carbon, the Ethiopian government, in an opportunistic move, took the lead in designing and launching the CRGE at the Durban (South Africa) COP of 2011.

It is also the case in Tanzania that the historical legacy of an interventionist state persists. Since the legislative system remains dominated by the ruling party which also controls both the state and the legislature (Elliott-Teague, 2007), the state dominates the policy regime (Cooksey, 2012). The implication of this is mostly felt in domestication of international agreements and policy making where some groups do not fully participate in the process and are partially excluded. These groups include smallholder farmers, pastoralists such as the Maasai, agro-pastoralists like the Sukuma and forest dependent communities such as the Barbaig, as well as those in the opposition.

\section{The Political Economy of Knowledge}

Finally, we focus on the politics of knowledge and expertise and the ways in which it frames the nature of the trade-offs countries face and the preferred means of dealing with them. In other words, whose knowledge counts? Given the complexity of the interface between climate and food and agricultural systems, policy makers depend on "epistemic communities" (Haas, 1990) of experts and advisers to advise on areas of consensus and uncertainty and to offer guidance about appropriate responses. From the authority which is deferred or delegated to them, scientists and other experts can accrue significant agenda-setting power as "knowledge brokers" (Litfin, 1994) that translate expert opinion into actionable interventions by states.

The presence of global institutions and knowledge brokers in the countries in question is significant here. In Kenya, the presence of major international research and development organizations such as the World Agroforestry Center (ICRAF), the United Nations Environment Programme (UNEP) and others means the opportunities for these institutions to directly engage and shape policy are pronounced. Rwanda also hosts the Sustainable Development Goals Center for Africa (SDGC/A) 
which plays a key role in terms of shaping the agenda for its Economic Development and Poverty Reduction Strategy (EDPRS) and influencing its strategic actions through provision of required technical support to align national priorities (through EDPRS) with SDGs. As a key knowledge implementation broker, the Ministry of Finance and Economic Planning (MINECOFIN) continues to be actively engaged in shaping the sector strategies through their active participation in knowledge seminars, review workshops and validation meetings. Additionally, once final draft strategies are available they are immediately shared with the ministry for final review and approval. At this stage, MINECOFIN undertakes an assessment of the sector's strategy compliance with EDPRS, SDGs and CAADP. As part of that process, the ministry also invites SDGC/A to review, comment and provide their inputs over the given sector strategy with regards to its compliance with SDGs targets.

External knowledge brokers such as FAO, IFAD, World Bank, and other major international agencies, are often involved in key policy and strategy development activities in the African region. International experts are frequently brought in to the region to advise and work with government staff during the formulation and development of sector strategies and programmes. For example, in Rwanda the development of the Fourth Strategic Plan for Agricultural Transformation, which is now under development, is being undertaken by international experts commissioned by FAO and European Union. These actors play an important steering role as knowledge brokers, serving as transmission belts for the ideas, methodologies, and preferred policy proscriptions of their funders. During the drafting of the Country Agriculture Sector Strategy Results Framework a retreat of MINAGRI high ranked staff and expert was facilitated by FAO. Another example is the process of Strategic Environmental Assessment (SEA) of the Agriculture Sector in Rwanda Development, 2011. This study was initiated, funded and commissioned by European Union Delegation in Rwanda. During this time, the study was conducted by a team of international experts from consortium Safege (a consulting firm based in Belgium).

Rwanda's Green Growth and Climate Resilience National Strategy was also funded by DFID through the Climate and Development Knowledge Network (CDKN) and developed by advisers at the Smith School of Enterprise and Environment at the University of Oxford. In the case of Kenya's national climate strategy, a CDKN sponsored advisor was placed directly in the Vice-President's Office to influence and oversee the process of its formulation. Given the nature of Rwanda's strategy, during its formulation and development each targeted sector including agriculture was assigned an international expert who worked with the sector stakeholders in order to gather accurate data and information about the sector. After data collection, review, analysis, processing, and packaging a sector working paper with more detailed information was produced. Following the production of the papers, the experts met and compiled the information gathered from different sectors into a single report. The final report is composed of 14 plans of actions and each plan has various targets and indicators and a proposed sector to lead its implementation under overall supervision of MINECOFIN and the Ministry of National Resources of Rwanda (MINIRENA) ensuring direct government buy-in to donor proscriptions.

In a similar vein, a project implementation support mission is conducted at least once per year by IFAD in Rome. Normally, this mission is composed of international experts who review progress on implementation, identify specific challenges and assess project compliance with project objectives, and its pertinence to national, regional and global targets (including the SDGs and CAADP, etc). At the end of their mission, these experts usually produce a report with a rating of the project performance against its design targets and propose key actions in order to improve the overall performance against different criteria.

The World Bank has also been analyzing CSA policy and implementation in Africa and other regions since 2016. The agency has designed a set of "CSA Policy Indicators" to assess the enabling environment in the form of policy and institutional frameworks, and services and infrastructure, within a country supporting the implementation of CSA (World Bank, 2016). The index is derived from 14 indicators (comprised of 31 sub-indicators) clustered into three broad themes: (1) Readiness Mechanism; (2) Services and Infrastructure, and (3) Coordination Mechanism aligned with the claimed "triple wins" of productivity, resilience, and mitigation to gauge the progress of countries in implementing CSA (World Bank, 2016; Braimoh et al., 2017). The CSA Policy Index is meant to enable policy makers to use the index to identify gaps and to assess the full potential to support implementation of Climate Smart Agriculture policies and programmes (Ijeoma et al., 2015; Braimoh et al., 2017). Specifically, it help policy makers and other practitioners gauge the extent to which policies, frameworks, economic structure, social structure, and governance structure are conducive for supporting CSA implementation. The first theme, the "Readiness Mechanism," refers to the capacity of countries to plan and deliver adaptation and mitigation programs in ways that are catalytic and fully integrated with national agricultural development priorities. It also measures the country's capacity to leverage investments for climate action and incentivise adoption of new technologies. The second theme, "Services and Infrastructure," measures the country's institutional capacity to mainstream CSA, including how effectively a country can mobilize and coordinate across its various ministries and stakeholders to support CSA implementation. The third theme, the "Coordination Mechanism," is designed to assess collaboration for disaster risk management and coordination among the sectors involved in CSA.

The World Bank's Africa Climate Business Plan (ACBP), which was launched at the 21st Session of the Conference of the Parties (COP 21) in Paris in 2015, calls for US\$19 billion in new funding to help the countries of the region to adapt to climate change and strengthen the continent's resilience to climate shocks. A review of the progress in implementing the ACBP using the CSA Policy Index and indicators was carried out in 2018 to assess the extent to which African countries have adopted CSA policies and created the enabling environment for implementation (World Bank, 2018). Most African countries scored low on the CSA policy indicators, especially the Readiness Mechanism, Services and Infrastructure, and an "Aggregated 
Policy Index" (linked to the "Coordination Index"). The review's findings indicates that they face critical challenges related to leveraging investments for climate action, promoting adoption of new technologies, providing enabling services, and creating the necessary institutions for CSA implementation.

Interestingly, of the four countries reviewed for this study, two countries-Tanzania and Rwanda-were among the top performers (with API scores of 75.6 and $73.3 \%$, respectively), while the other two-Kenya and Ethiopia-fell just below the average of $60.1 \%$ at 58.6 and $57.9 \%$.

Tanzania's relatively high score in the index (API of $76 \%)$ is driven primarily by its scores in Services and Infrastructure and Coordination Mechanisms, as described above. Its commitment to addressing climate adaptation and mitigation in the agriculture sector is reflected in the country's NAPA and National Climate Change Strategy. Beyond these two plans, the National Strategy for Growth and Reduction of Poverty (NSGRP II) also incorporates climate change as a crosscutting issue. With an API score of 73\%, Rwanda is another top performer in the index. Its commitment to CSA is reflected in the National Strategy for Climate Change and Low Carbon Development. The strategy includes a monitoring framework for its mitigation and adaptation programmes and involves various ministries, including MINAGRI, as well as the Ministry of Infrastructure (MININFRA) and Municipal Authorities, in its implementation. The country's Strategic Program for Climate Resilience (SPCR) developed through a multi-stakeholder process focuses on agricultural resilience, sustainable landscapes, and strengthening institutional capacity among others. The country also has established several public-private partnerships to develop services and infrastructure, such as crop insurance that have the potential to create a strong enabling environment for CSA. Compared to most other African states, Rwanda also scored highly in agricultural adaptation policy, agricultural mitigation policy, agricultural $\mathrm{R} \& \mathrm{D}$, social safety nets, national GHG inventory system, and disaster risk management coordination.

In providing strategic advice and evidence, the World Bank, and other international agencies are acting as key interlocutors between expert communities and policy-makers, evaluating project and policy compliance. Knowledge brokers from scientific, economic and technical institutions, including international agencies and consultancies, play an important part in shaping how governments respond to the trade-offs of governing SDGs and CSA in practice.

\section{CONCLUSIONS}

In this paper we have sought to improve upon understandings of the diverse ways in which governments are coming to terms with the synergies and trade-offs around the simultaneous implementation of SDGs, in particular how it relates to climate change and agriculture. Using the example of climate smart agriculture, our analysis has sought to generate explanations for that diversity based on an account of governance and the role of the state, the ways in which commitments are translated and domesticated, the degree of policy autonomy and developmental space countries have to align global goals and indicators with their own national circumstances and preferences, and finally the role of knowledge brokers in identifying areas for intervention and shaping the preferred metrics of evaluation and performance. The interface between climate change and agriculture is particularly key in a region of the world where its effective and inclusive management is vital to the livelihoods of millions of the poor. Despite the proliferation of guides, indicators and "tool-kits" for SDG implementation and the growing market for consultancy in helping governments demonstrate compliance with the 17 global goals and 232 indicators, we have argued that there is a pressing need to understand the different routes by which states, market actors and civil societies in different parts of the world will manage the simultaneous implementation of goals across competing policy areas, where vested interests and nested networks are battling for resources and authority in financially constrained environments. There is often a gap then between "global imaginaries" of how the SDGs will be delivered and the messy political economy of everyday implementation. The reality of how different regions and social groups deal with these challenges on the ground is often very different from the way projects are imagined by donors and multilateral development banks and regional institutions.

Others have noted a "triple disconnect" between the global, national, and local scales as the trade-offs inherent in dealing with the political and ecological connections between SDGs are negotiated across levels of authority (Karlsson et al., 2018). Added to this is the fact that the language of "synergy" and "integration" around the SDG objectives masks the reality of institutional jockeying for position between global governance institutions at the international level, among governmental departments at the national level, and between national and local government actors who seek to position themselves to benefit from new resource flows associated with climate finance and the SDGs (Newell et al., 2018).

Our findings here lend weight to those conclusions where we have found that this competition tends to reproduce siloed policy practices within government and development agencies. Siloes and sector-based approaches become entrenched because financial and decision-making lines of authority are sector-based. Trade-offs and turf wars exist not just between ministries at national level, but between central and local government, as we saw in the case of Kenya. Due to devolution, the national government ministries only set the broad policy agenda as agricultural policy is devolved to county level. They, therefore, do not have to navigate the trade-offs. The difficult politics of translation get consciously delegated downwards.

Global interventions look different once translated into diverse domestic political and economic settings and refracted through local institutional processes. But this is not just about weaker states having policies imposed from above or outside. The case of aid-dependent Ethiopia asserting its autonomy affords an interesting case in point. As others have noted, competition between agencies, differing interests, and the very ambiguity of terms such as CSA, can create opportunities, as well as challenges, for national and local government officials to acquire authority 
and resources by invoking the label "climate smart" (Newell and Taylor, 2018). For example, a Ministry of Agriculture official in Kenya noted that "CSA has become synonymous with best practice agricultural interventions....Arguably, every project in Kenya is climate linked and is therefore "climate smart" ... Nowadays even the roads have to be "climate smart!" (pers. comm. 2017).

This underscores the need to engage with the "messy" politics of SDG implementation in a diversity of contexts and not assume there are easily transferable ways of getting countries to manage the inter-linkages between SDGs. As Naess et al. argue (2015, p. 543) "attempts to work with or against the grain of politics in a particular setting require an appreciation of the social and political networks and relations of power which will determine how the trade-offs inherent to climate change and development goals are worked through and on whose behalf." Strategies will have to go with the grain and reflect national political, economic, and socio-cultural circumstances (Booth and Golooba-Mutebi, 2014), understanding where political settlements lie (Khan, 2010) and where scope exists for building alliances of actors around more inclusive and progressive visions of climate smart agriculture compatible with the SDGs.

This paper thus illustrates the value of political economy analysis. It can help explain how incumbent power and resistance to change and why power inequities and institutional inertia make change hard to achieve. Furthermore, it can also show where windows of opportunity might lie, where new alliances might be possible and alternative framings might open up spaces for policy responses that are more attuned to the needs of poorer groups, and that leave open multiple avenues of agricultural development that are compatible with the twin needs for decarbonization and resilience, rather than locking in one dominant trajectory.

Regarding the strategic and political value of exploring these possibilities, we concur with the assertion that "apart from the argument that integration of climate policy and development goals can achieve synergies, improve effectiveness and avoid trade-offs, we consider that their integration would be likely to increase the social acceptability and political feasibility of

\section{REFERENCES}

Adhikari, U., Nejadhashemi, A. P., and Woznicki, S. A. (2015). Climate change and eastern Africa: a review of impact on major crops. Food Energy Security 4, 110-132. doi: 10.1002/fes3.61

African Union (2015). Malabo Declaration on Accelerated Agricultural Growth and Transformation for Shared Prosperity and Improved Livelihoods. African Union Commission, Addis Ababa.

Allouche, J., Middleton, C., and Gyawali, D. (2019). The Water-Food-Energy Nexus: Power, Politics and Justice. Pathways to Sustainability Series. London: Routledge; Earthscan Publications.

Beg, N., Morlot, J. C., Davidson, O., Afrane-Okesse, Y., Tyani, L., Denton, F., et al. (2002). Linkages between climate change and sustainable development. Clim. Policy 2, 129-144.

Berhanu, K., and Poulton, C. (2014). The political economy of agricultural extension policy in ethiopia: economic growth and political control. Develop. Policy Rev. 32, s197-s213. doi: 10.1111/dpr.12082 emissions reductions in contexts and countries where historical contributions to climate change have been negligible" (Naess et al., 2015, p. 535). Indeed, political economy analysis for examining the challenges and opportunities for implementing "climate-resilient agriculture" for achieving multiple SDGs cannot be reduced to a generic tool to manage change on terms set by powerful external actors, nor as a shorthand for highlighting governance failures in already weak and struggling states. Rather, it should serve as a useful starting point for an informed discussion about who is benefiting, and more importantly, who is not, from existing ways of addressing multiple goals, how and why this is the case, and what can be done about it (Naess et al., 2015).

Viewed this way, the challenge of identifying inter-linkages across SDGs, isolating potential big "wins" around multiple synergies and minimizing negative trade-offs cannot be reduced to a technocratic mapping or benchmarking exercise. Nor can it result in plug-in "one size fits all" toolkits that countries can adopt. Foregrounding questions of power, politics, political economy, governance, institutions, and knowledge is not designed only to demonstrate the importance of context or the need to engage with the messy realities of policy implementation. It also allows us to identify which pathways to managing SDGs are being designed, why, on whose behalf and with what implications. That surely is the starting point for constructing processes that are more inclusive, sustainable and effective in delivering a truly "smart" and even transformative agricultural future for all in a warming world.

\section{AUTHOR CONTRIBUTIONS}

All authors made direct contributions to the work through the production of mapping papers for this project or the direct writing of this paper.

\section{FUNDING}

This research was generously supported by the Sussex Sustainability Research Programme. 
Cole, D. H. (2015). Advantages of a polycentric approach to climate change policy. Nat. Clim. Chang. 5, 114-118. doi: 10.1038/nclimate2490

Cooksey, B. (2012). Politics, Patronage and Projects: The Political Economy of Agricultural Policy in Tanzania. FAC Working Paper 40. Brighton: Future Agricultures Consortium. Available online at: https://www.futureagricultures.org/publications/working-papers-document/politics-patronageand-projects-the-political-economy-of-agricultural-policy-in-tanzania/ (accessed April 12, 2019).

CTA (2016). COP 22 Action for Agriculture Press Communique. Wageningen: Technical Centre for Agricultural and Rural Cooperation ACP-EU. http:// www.cta.int/en/article/2016-11-14/cop22-n-action-for-agriculture.html (accessed April 12, 2019).

Davidson, O., Halsnaes, K., Huq, S., Kok, M., Metz, B., Sokona, Y., and Verhagen, J. (2003). The development and climate nexus: the case of sub-Saharan Africa. Clim. Policy, S97-S113.

Elliott-Teague, G. (2007). NGOS in Policymaking in Tanzania: The Relationships of Group Characteristics, Political Participation and Policy Outcomes. Thesis Submitted in partial fulfillment of the requirements for the degree Doctor of Philosophy, School of Public and Environmental Affairs, Indiana University, Bloomington, IN, United States.

Ellis, K., Baker, B, and Lemma, A. (2009). Policies for Low Carbon Growth. ODI Research Report, ODI, London, 1-80.

England, M. I., Dougill, A. J., Stringer, L. C., Vincent, K. E., Pardoe, J., Kalaba, F. K., et al. (2018). Climate change adaptation and cross-sectoral policy coherence in Southern Africa. Region. Environ. Change 18, 2059-2071. doi: 10.1007/s10113-018-1283-0

FAO (2013a). Climate-Smart Agriculture: Sourcebook. Rome: Food and Agriculture Organization of the United Nations.

FAO (2013b). Statistical Yearbook 2013: World Food and Agriculture. Rome: Food and Agriculture Organization of the United Nations.

FAO (2014). FAO Success Stories on Climate-Smart Agriculture. Rome: Food and Agriculture Organization of the United Nations.

FAO (2017a). Climate-Smart Agriculture. Rome: Food and Agriculture Organization of the United Nations. Available online at: http://www.fao. org/climate-smart-agriculture/en/ (accessed April 12, 2019).

FAO (2017b). Regional Analysis of the Nationally Determined Contributions of Eastern Africa, Gaps and Opportunities in the Agriculture Sectors. Rome: Food and Agriculture Organization of the United Nations.

FAO (2018). Statistical Pocketbook 2018. Rome: Food and Agriculture Organization of the United Nations.

FDRE (2012). Ethiopia's Climate Resilient Green Economy Facility Terms of Reference. Final Version (August 2012). Addis Ababa: Ministry of Finance and Economic Development, Government of Ethiopia.

Gallagher, K. (ed.). (2005). Putting Development First: The Importance of Policy Space in the WTO and International Financial Institutions. London: Zed Books.

Government of Kenya (2010). Constitution of Kenya. Available online at: http:// www.kenyalaw.org/Downloads/The\%20Constitution\%20of\%20Kenya.pdf (accessed July 1, 2019).

Haas, P. M. (1990). Obtaining international environmental protection through epistemic consensus. Millennium J. Int. Studies. 19, 347-363. doi: $10.1177 / 03058298900190030401$

Haywood, L. K., Funke, N., Audouin, M., Musvoto, C., and Nahman, A. (2018). The sustainable development goals in south africa: investigating fhe need for multi-stakeholder partnerships. Develop. South. Africa 2018, 1-15. doi: 10.1080/0376835X.2018.1461611

Ijeoma, E., Braimoh, A., Heumesser, C., Rawlins, M., and Zhao, Y. (2015). "Developing indicators for Climate Smart Agriculture (CSA)," in Presentation at the Climate Smart Agriculture Conference (Montpellier), 16-18.

IPCC (2014). Climate Change 2014: Synthesis Report. Contribution of Working Groups I, II and III to the Fifth Assessment Report of the Intergovernmental Panel on Climate Change [Core Writing Team, R.K. Pachauri and L.A., Meyer (eds.)]. Geneva: Intergovernmental Panel on Climate Change.

Karlsson, L., Naess, L. O., Nightingale, A., and Thompson, J. (2018). 'Triple Wins' Or 'Triple Faults'? analysing the equity implications of policy discourses on climate-smart agriculture (CSA). J. Peasant Stud. 45, 150-174. doi: $10.1080 / 03066150.2017 .1351433$

Kateka, A. (2016). "Policies Legal Frameworks and Institutions Governing Pastoral Systems in East Africa," in Pastoralism and Climate Change in East Africa, eds P. Z. Yanda and C. G. Mung'ong'o (Dar es Salaam: Mkuki na Nyota), 157-198.

Keeley, J., and Scoones, I. (2003). Understanding Environmental Policy Processes: Cases from Africa. London: Earthscan.

Khan, M. (2010). Political Settlements and the Governance of Growth-Enhancing Institutions. London: Research Paper Series on Governance for Growth. School of Oriental and African Studies.

Khan, M. A., and Akhtar, M. S. (2015). "Agricultural adaptation and climate change policy for crop production in Africa," In Crop Production and Global Environmental Issues. eds K. Hakeem K (Cham: Springer), 437-541.

Lipper, L., Thornton, P., Campbell, B. M., Baedeker, T., Braimoh, A., Bwalya, M., et al. (2014). Climate-smart agriculture for food security. Nat. Climate Change 4:1068. doi: $10.1038 /$ nclimate 2437

Litfin, K. (1994). Ozone Discourse: Science and Politics in Global Environmental Cooperation. Columbia: Columbia University Press.

Mitchell, T., and Maxwell, S. (2010). Defining Climate Compatible Development. CDKN ODI Policy Brief, 1-6.

Miyan, M. A. (2015). Droughts in asian least developed countries: vulnerability and sustainability. Weather Climate Extrem. 7, 8-23. doi: 10.1016/j.wace.2014.06.003

Naess, L., Newell, P., Newsham, A., Phillips, J., Quan, J., and Tanner, T. (2015). Climate policy meets national development contexts: insights from Kenya and Mozambique. Glob. Environ. Change 35, 534-544. doi: 10.1016/j.gloenvcha.2015.08.015

National Planning Commission (2015). The Growth and Transformation Plan II (2016-2020). Addis Ababa: Government of Ethiopia.

Newell, P. (2008). 'Lost in translation? domesticating global policy on GMOs: comparing India and China'. Global Soc. 22, 117-138. doi: 10.1080/13600820701740761

Newell, P., and Taylor, O. (2018). Contested landscapes: the global political economy of climate smart agriculture. J. Peasant Stud. 45, 108-130. doi: 10.1080/03066150.2017.1324426

Newell, P., Taylor, O., and Tonui, C. (2018). Governing food and agriculture in a warming world. Glob. Environ. Polit. 18, 53-71. doi: 10.1162/glep_a_00456

Nunan, F. (ed.). (2017). Making Climate Compatible Development Happen. London: Routledge.

Olsson, L., Opondo, M., Tschakert, P., Agrawal, A., Eriksen, S. H., Ma, S., et al. (2014). "Livelihoods and poverty," in Climate Change 2014: Impacts, Adaptation, and Vulnerability. Part A: Global and Sectoral Aspects. Contribution of Working Group II to the Fifth Assessment Report of the Intergovernmental Panel on Climate Change. eds C. B. Field, V. R. Barros, D. J. Dokken, K. J. Mach, M. D. Mastrandrea, T. E. Bilir, M. Chatterjee, K. L. Ebi, Y. O. Estrada, R. C. Genova, B. Girma, E. S. Kissel, A. N. Levy, S. MacCracken, P. R. Mastrandrea, and L. L. White (Cambridge: Cambridge University Press), 793-832.

Oqubay, A. (2015). Made in Africa: Industrial Policy in Ethiopia. Oxford: Oxford University Press. doi: 10.1093/acprof:oso/9780198739890.001.0001

Phillips, J., Newell, P., and Pueyo, A. (2017). "Triple wins? Prospects for propoor, low carbon, climate resilient energy services in Kenya,"' in Making Climate Compatible Development Happen, ed F. Nunan (Oxon: Routledge), 114-130.

Quan, J., Otto Naess, L., Newsham, A., Sitoe, A., and Corral Fernandez, M. (2014). "Carbon forestry and climate compatible development in Mozambique: a political economy analysis," in IDS Working Papers, Vol. 2014, 1-40.

Rai, N., and Fisher, S. (2016). Understanding the politics of low carbon development in the least developed countries. in The Political Economy of Low Carbon Resilient Development: Planning and Implementation. eds N. Rai and S. Fisher (New York, NY: Taylor and Francis), 1-22.

REMA (2011). National Strategy for Climate Change and Low-Carbon Development 'Green Growth and Climate Resilience'. Kigali: Rwanda Environment Management Authority.

Scott, A. (2017). Making Governance Work for Water-Energy-Food Nexus Approaches. CDKN Working Paper (July 2017). London: Climate and Development Knowledge Network.

Smalley, R. (2017). Agricultural Growth Corridors on the Eastern Seaboard of Africa: An Overview. APRA Working Paper 1. Agricultural Policy Research in Africa (APRA) Programme. Brighton: Future Agricultures Consortium. 
Sorecha, E. M. (2017). Growth and survival rate of endemic trees of ethiopia: olea africana and hagenia abysinicca in lake haramaya watershed, eastern Ethiopia. J. Horticult. Forest. 9, 33-39. doi: 10.5897/JHF2017.0486

Sovacool, B., and Linnér, B. (2016). The Political Economy of Climate Change Adaptation. Basingstoke, UK: Palgrave Macmillan.

Sovacool, B. K., Tan-Mullins, M., Ockwell, D., and Newell, P. (2017). Political economy, poverty, and polycentrism in the global environment facility's least developed countries fund (LDCF) for climate change adaptation. Third World Quart. 38, 1249-1271. doi: 10.1080/01436597.2017.1282816

Suckall, N., Tompkins, E., and Stringer, L. (2014). Identifying trade-offs between adaptation, mitigation and development in community responses to climate and socio-economic stresses: evidence from zanzibar, Tanzania. Appl. Geography 46, 111-121. doi: 10.1016/j.apgeog.2013.11.005

Tanner, T., and Allouche, J. (2011). Towards a new political economy of climate change and development. IDS Bull. 42, 1-14. doi: 10.1111/j.1759-5436.2011.00217.x

Tanner, T., Mensah, A., Lawson, E. T., Gordon, C., Godfrey-Wood, R., and Cannon, T. (2014). Political Economy of Climate Compatible Development: Artisanal Fisheries and Climate Change in GHANA. IDS Working Papers, 1-30. doi: 10.1111/j.2040-0209.2014.00446.x

Taylor, M. (2015). The Political Ecology of Climate Change Adaptation. London: Earthscan.

Taylor, M. (2018). Climate-smart agriculture: what is it good for? J. Peasant Stud. 45, 89-108. doi: 10.1080/03066150.2017.1312355

United Nations (2015). Transforming Our World: The 2030 Agenda for Sustainable Development. Available online at: https://sustainabledevelopment. un.org/post2015/transformingourworld (accessed April 12, 2019).

URT (2006). Mkakati wa Hatua Za Haraka Za Kuhifadhi Mazingira Ya Ardhi Na Vyanzo Vya Maji, Makamu Wa Rais. Dar es Salaam: Vice Presidents Office, United Republic of Tanzania.

URT (2009). Jarida la Umasikini na Mazingira, Makamu wa Rais. Dar es Salaam: Vice President's Office, Division of Environment, United Republic of Tanzania.
URT (2013). National Agriculture Policy. Dar es Salaam: Ministry of Agriculture, Livestock and Fisheries, United Republic of Tanzania.

Vermeulen, S. J., Campbell, B. M., and Ingram, J. S. I. (2012). Climate change and food systems. Annu. Rev. Environ. Resour. 37, 195-222. doi: 10.1146/annurev-environ-020411-130608

Vorley, B., Cotula, L., and Chan, M. K. (2012). Tipping the balance: policies to shape agricultural investments and markets in favour of small-scale farmers. Oxfam Policy Pract. 9, 59-146. doi: 10.21201/2012.2288

Wade, R. (2003). 'What strategies are viable for developing countries today? the world trade organization and the shrinking of 'development space'. Rev. Int. Politic. Econ. 10, 621-644 doi: 10.1080/096922903100016 01902

Weitz, N., Strambo, C., Kemp-Benedict, E., and Nilsson, M. (2017). Closing the governance gaps in the water-energy-food nexus: insights from integrative governance. Global Environ. Change 45, 165-173. doi: 10.1016/j.gloenvcha.2017.06.006

World Bank (2016). Climate Smart Agriculture Indicators. World Bank Group Report No. 105162-GLB. Washington, DC: World Bank.

World Bank (2018). Scaling Up Climate-Smart Agriculture through the Africa Climate Business Plan. Washington, DC: World Bank.

Conflict of Interest Statement: The authors declare that the research was conducted in the absence of any commercial or financial relationships that could be construed as a potential conflict of interest.

Copyright (c) 2019 Newell, Taylor, Naess, Thompson, Mahmoud, Ndaki, Rurangwa and Teshome. This is an open-access article distributed under the terms of the Creative Commons Attribution License (CC BY). The use, distribution or reproduction in other forums is permitted, provided the original author(s) and the copyright owner(s) are credited and that the original publication in this journal is cited, in accordance with accepted academic practice. No use, distribution or reproduction is permitted which does not comply with these terms. 